\title{
Crusher Design for Plastic Waste in 3D Printing
}

\author{
Cedric Rahardjo ${ }^{1, a}$, Yopi Yusuf Tanoto ${ }^{2, b}$, Ninuk Jonoadji ${ }^{3, c}$ \\ ${ }^{1}$ College of Applied Sciences, National Taiwan University of Science and Technology, Taiwan \\ ${ }^{2,3}$ Mechanical Engineering Department, Petra Christian University, Jalan Siwalankerto 121-131, Surabaya 60236, Indonesia \\ ${ }^{a}$ Cedricrahardjo@gmail.com, byopi.tanoto@petra.ac.id, ${ }^{c}$ ninukjepetra.ac.id
}

\begin{abstract}
D printing is a manufacturing process widely used in the 4.0 Industry era. One of the concepts of 3D printing is to make prototypes, whether it is for industrial purposes or studying purposes. Knowing that a prototype is only needed in the early stages of any process, it is bound to be redundant in a short time; thus, the plastics used to prototype using the 3D printing technology are now labeled as waste. Since most plastics used for 3D printing are thermoplastics, they can be recycled to live another purpose. This research aims to design a crusher dedicated to processing 3D printing waste as the first step towards recycling these wasted materials. This step encourages students to comprehend the process of designing and manufacturing such equipment while also opening doors for the faculty towards recycling 3D printed plastics. The designing process consists of surveying the materials commonly used for 3D printing, calculating the machine elements, choosing the mechanism needed to destroy the material, and designing a model from the calculations. The outcome of the design is a device that can crush and destroy PLA (Polylactic Acid) and ABS (Acrylonitrile Butadiene Styrene) plastics into pieces ready for recycling.
\end{abstract}

Keywords: 3D printing, crusher, PLA, ABS.

\section{Introduction}

Technological developments have increased rapidly along with world growth, especially in the Industry 4.0 era. As the industry sector keeps evolving, creativity in product design is key to striving in the market competition [1].

Industrial development requires tools that have high accuracy and fast manufacturing time to simplify the production process, such as the tools used to make prototypes, so that industries apply CNC (Computer Numerical Control) machines in their production processes. CNC machines have developped amazingly because $\mathrm{CNC}$ machines can make various workpieces with minimum trouble.

3D Printing is one of the technological innovations in the industrial era 4.0. [3] said that a 3D printer is a fabrication tool for manufacturing additives used for prototyping. Some of the technologies often used in 3D printing are Selective Laser Sintering (SLS), stereolithography, and fused deposition modeling.

A 3D printer is getting more popular in Indonesia because it helps humans to make prototypes easily. Prototyping activities usually take a relatively long time because they go through several stages, from design to finishing. Therefore, 3D printing technology began to be made to carry out prototyping activities effectively and efficiently. The FDM (Fusion Discharge Machining) type 3D printer uses plastic-based raw materials such as Polylactic Acid (PLA), Acrylonitrile Butadiene Styrene (ABS), and Polyethylene Terephthalate Glycol (PETG) [4]. After being used in the 3D printing process, these filamentous raw materials often become plastic waste that has the potential to be recycled. $3 \mathrm{D}$ printing is expected to be a solution to solve problems in the industrial world. However, this technology requires plastic raw materials, which are often taken from nature.

One way to reduce excessive plastic use in $3 \mathrm{D}$ printing is by recycling the $3 \mathrm{D}$ printing results that are no longer used (supports, rafts, trees) and failed or defective 3D printing results. By recycling the results of $3 \mathrm{D}$ printing, virgin plastic can be minimized [5].

\section{Research Methods}

This process includes the collection of materials to be recycled (PLA and ABS waste from the $3 \mathrm{D}$ printing process), which are mostly obtained from the 3D printing laboratory of Petra Christian University and the author's personal waste. Some of the collected waste is then sorted and differentiated by color. A tough challenge is that the plastic waste from the 3D printer is often not sorted according to the material, so it is difficult to distinguish ABS and PLA. This causes some unknown waste made from PLA or ABS.

For laboratory purposes, the capacity of the crusher machine is designed to be $1 \mathrm{~kg} /$ hour. In addition, the machine is designed to be easily manufactured with the help of laser cutting, so all calculations and modeling is based on the laser cutting process.

The modeling process was carried out using Autodesk Inventor 2019, and several calculations regarding the strength of the material through stress analysis were also carried out using Autodesk Inventor 2019. The crusher machine is divided into four parts: the hopper, cutterbox, frame, and power system. Where the cutterbox is the main component of the crusher machine which will be laser cut. 


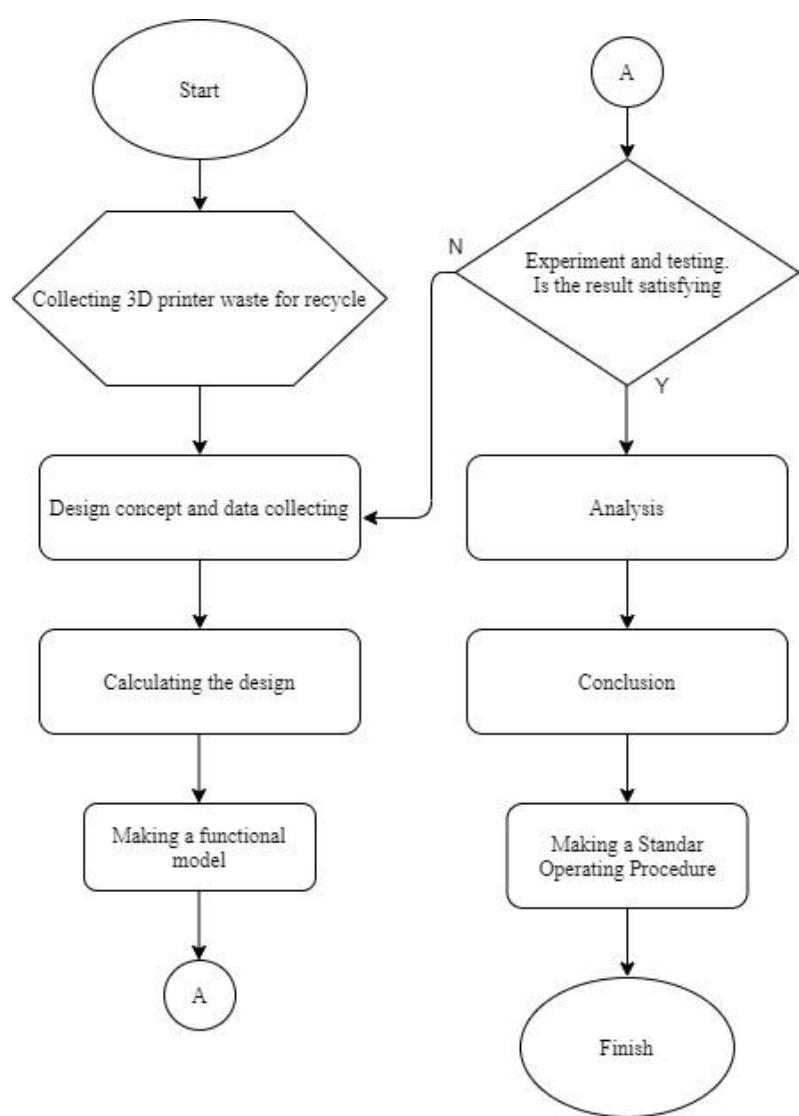

Figure 1. Research Flowchart.

\section{Results and Processes}

\subsection{Machine Design}

The crusher machine manufacturing process starts from drawing the design through the $\mathrm{CAD}$ Inventor software. The machine design is made so that it can be produced using a laser cutting machine. The following is a whole sighting of the cutterbox assembly.

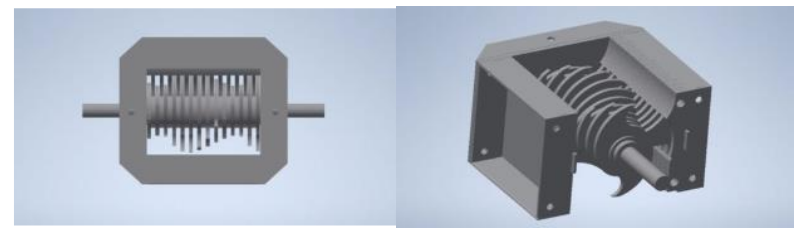

Figure 2. Cutter box model

The blade design used is a design by Dave Hakkens, which has been proven to chop plastic with minimum force. The total number of blades is 14 and are assembled with a difference of 20 degrees. With a blade configuration like this, only two blades are allowed to contact an object at once, increasing the crusher machine's ability to destroy objects that have tough properties. The series of blades and shear knives can be seen in Figure 3.

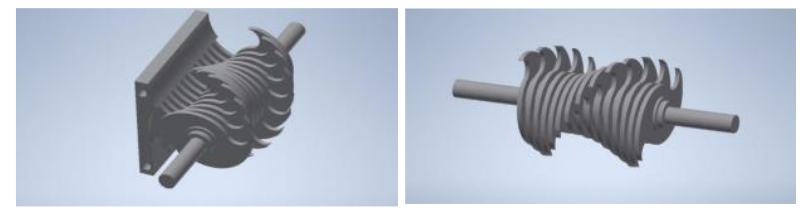

Figure 3. Blade and counterknife.
Designing the gap of each blade is key to having an effective cut. Fundamentally having the gap as narrow as possible is preferred for the machine to cut materials, However having a narrow gap also poses a challenge where the tolerance of the blade surface and poor counterknife can cause excessive friction or cause the blade to hit the counterknife, causing heavy damage. Therefore the shape of the blade tip has been modified to make it more streamlined when rotating towards the counterknife in order to avoid collisions with the counterknife. It can be seen in Figure 4 that the tip of the blade has a straight and sharp edge but has an angle that points into the radius.

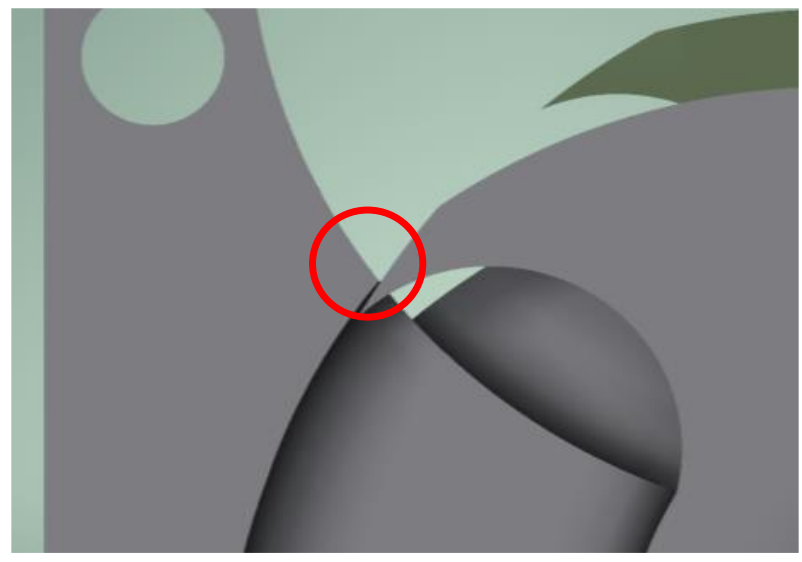

Figure 4. Blade and counterknife 'gap'.

\subsection{Laser cutting}

The laser cutting process that is carried out is the easiest and fastest process but requires a fair amount of money. Acceptance of laser cutting services receives a CAD file in the form of .DXF, which can be obtained from the conversion from Autodesk Inventor. The laser cutting process is divided into several parts according to the thickness of the plate. For the front frame, rear frame, and spacers, a $3 \mathrm{~mm}$ mild steel plate is used. As in for the counter knife and blades, stainless steel plate with $5 \mathrm{~mm}$ thickness is used. For the side frame, shredding spacer, and sieve plate, mild steel with a thickness of $6 \mathrm{~mm}$ was used.

The result of the laser-cutting process is a part that has good precision and accuracy, which gives the crusher machine's performance improvement. The results of the laser cut are shown in Figure 5.
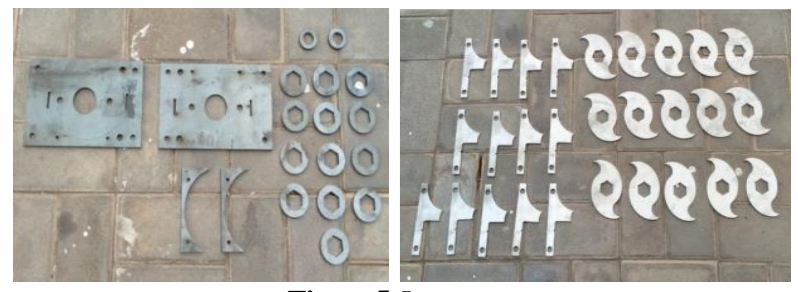

Figure 5. Laser-cut parts

\subsection{Assembly}

Once all parts have been printed, then all of them are installed. The installation process is quite simple with minimal frame welding, and the rest can be easily assembled using a bolt-on system. The assembly process can be seen in Figure 6 and Figure 7. 


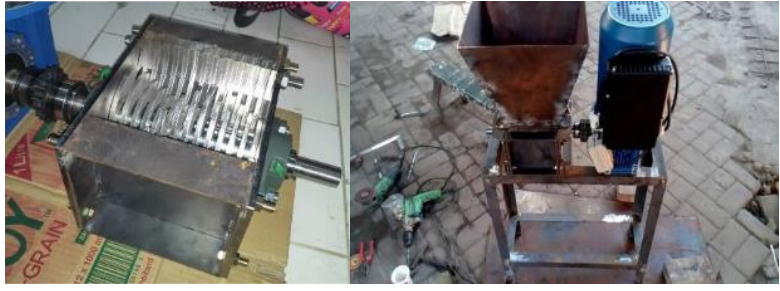

Figure 6. Cutter box assembly (left) and final assembly (right)

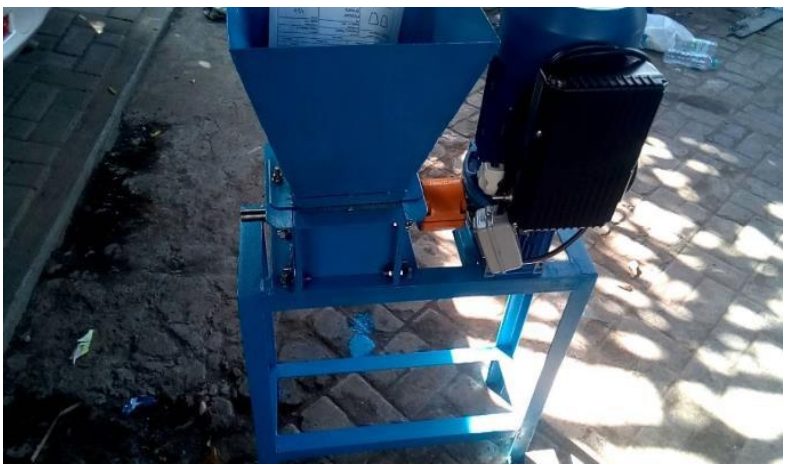

Figure 7. Paint is used to protect the machine against oxidization

\subsection{Experiments and testing}

The test results are based on PLA and ABS materials in accordance with the problem limits set at the beginning. In the trial, PLA and ABS materials were used, which have been divided into two types of waste. The first type is soft waste in the form of support, raft, skirt, and failed prints that do not have a clear shape (as shown in Figure 8). The second type is the hard waste from 3D printing that is no longer used, which still has a clear shape (as shown in Figure 9).

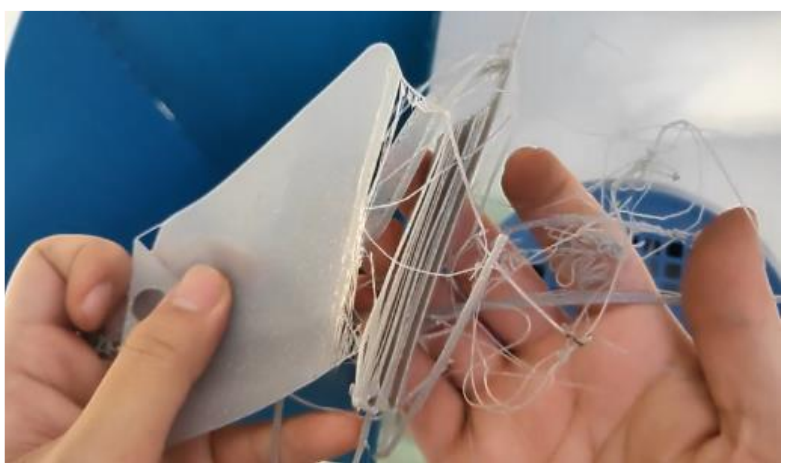

Figure 8. Soft-waste before crushed.

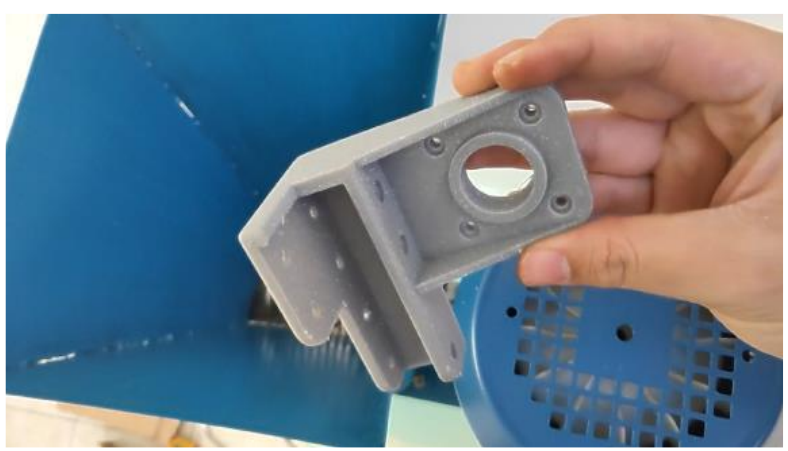

Figure 9. The hard waste before crushed
The processed PLA and ABS materials have relatively the same results, with varying flake sizes from small to large, so it takes several times the crushing process (without a filter) to achieve the desired results (Figure 10). However, the crushing process takes a little longer with the filter installed, but the output flakes that come out of the crusher machine have a much better and consistent result (Figure 11).

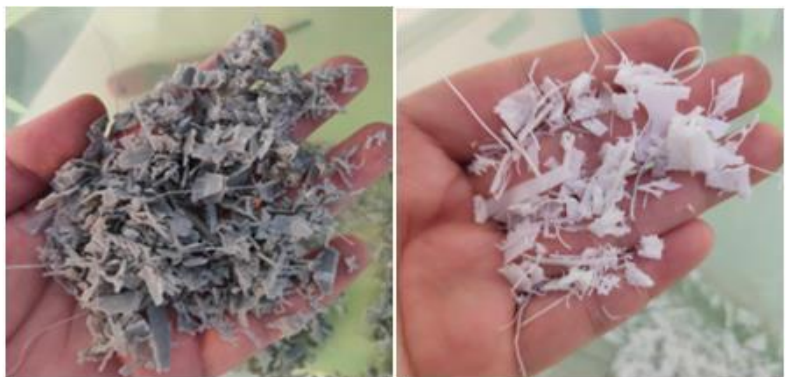

Figure 10. Unfiltered crushing of ABS(left) and PLA(right).

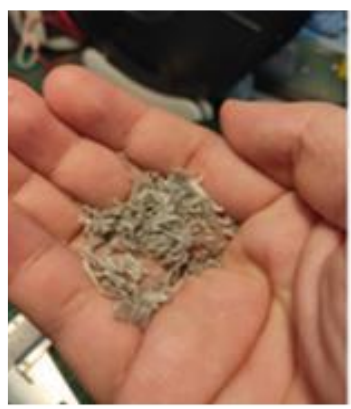

Figure 11. filtered crushing

The crusher machine capacity experiment were also carried out by inserting $1 \mathrm{~kg}$ of material and then recording the time required by the crusher machine to process this amount of material. For $1 \mathrm{~kg}$ material, the time is 41 minutes. From this capacity experiment, it can be concluded that the crusher machine has a capacity of $1.5 \mathrm{~kg} /$ hour.

\section{Conclusion}

The design of a crusher machine for waste plastic 3D printers has been done well. The design has also been implemented and tested. The design resulted in the machine being capable of crushing PLA and ABS materials with a capacity of $1.5 \mathrm{~kg} /$ hour. The maximum size of an object that can enter the machine is $14 \times 12 \mathrm{~cm}$.

Based on the test results, this machine has met the stated objectives. The calculations that have been done produce good results so that the crusher machine can destroy PLA and ABSbased plastics as expected.

After further testing, several limitations were found from the machine in the form of a relatively small mouth size $(14 \mathrm{~cm}$ $\mathrm{x} 12 \mathrm{~cm}$ ) so that when you want to destroy a large object, the object must first be minimized using a hammer or cutting tool.

Another thing that needs to be considered is the maintenance of the crusher machine, which must be done after every use. Plastic debris sandwiched between the blades can create excess friction and reduce crusher machine performance. This machine is also easy to use mainly because it only has two function buttons; the on-off switch and reverse control. 


\section{References}

[1]. Sumantri, Dede. Peningkatan Kinerja Mesin Rapid Prototyping Berbasis Fused Desposition Modelling. Skripsi. Jakarta: Universitas Indonesia.(2012).

[2]. Sumbodo, W.dkk. Teknik Produksi Mesin Industri. Jakarta: Direktorat Pembinaan Sekolah Menengah Kejuruan. (2012) p.34-35.

[3]. More, M. P. 3D Printing Making the Digital Real. International Journal of Engineering Science \& Research Technology. p.4 (2013)

[4]. Joe, A. D. Design and Construction of a Plastic Shredder. Nigeria: International Journal of Scientific \& Engineering Research Volume 9, Issue 5(2018).

[5]. Raju, S. R. Design and Development of mini plastic shredder machine. Delhi: IOP Conference Series: Materials Science and Engineering (2018).
[6]. Ravi, S. (2018). Utilization of Upgraded Shredder Blade and Recycling the. Paris, France: Proceedings of the International Conference on Industrial Engineering and Operations Management.

[7]. Adhiharto, R. (2019). Studi Rancang Bangun Mesin Plastic Waste Shredder Dengan kapasitas 15 Kg/hari Degnan Aplikasi Metode VDI2222. Bandung: Jurusan Teknik Perancangan Manufaktur, Politeknik Manufaktur Negeri Bandung.

[8]. Sy, D. (2015). Material and Application Report 2015 Acrylonitrile Butadiene Stryene(ABS) and $3 D$ printer (2). RMIT.

[9]. Van der Leer, J. G. G. (2016). Zero Waste Buiksloterham: an Integrated Approach to Circular Cities.

[10]. Kim, H. J., \& Fairfax, D. (2017). A Study on the Development of Living Products from Recycled Plastic Water Bottles: Focus on the Closed-loop System Using 3D Printing Technology 